\title{
Ocean wave mapping from ERS SAR images in the presence of swell and wind waves*
}

\author{
STÉPHAN ROUSSEAU and PHILIPPE FORGET \\ ${ }^{1}$ Instituto de Ciencias del Mar, CSIC, P. Maritimo, 08039 Barcelona, Spain. Now at Centre de Sécurité des Navires \\ d'Aquitaine, 1 rue Fondaudège, 33000 Bordeaux, France. E-mail: rousseau.stephan@equipement.gouv.fr \\ ${ }^{2}$ Laboratoire de Sondages Electromagnétiques de l'environnement Terrestre, CNRS, Université de Toulon et du Var, \\ BP 132 La Garde Cedex, France. e-mail: forget@1seet.univ-tln.fr
}

\begin{abstract}
SUMMARY: We present a method for estimating the significant wave height of ocean waves $(S W H)$ in coastal zones from satellite SAR images and using the value of the width of the spectral azimuthal cutoff. The method deals with the case of an energetic swell propagating over a wind wave system. It requires the preliminary retrieval of swell parameters using the wave-SAR spectral quasi-linear relationship. The method is applied to two ERS-1 SAR images in coastal zones.

Key words: SAR imagery, ocean waves, significant wave height.

RESUMEN: CARTOGRAFía DEL CAMPO DE OLAS OCEÁNICAS CON IMÁGENES SAR ERS EN EL CASO DE MAR DE FONDO Y OLAS DE VIENTO. - Presentamos un método para estimar la altura significativa de las olas oceánicas en zonas costeras usando imágenes satélites SAR. El método emplea el valor de la anchura del corte espectral en azimut y se aplica sobre el caso de la combinación de un mar de fondo energético con un sistema de olas de viento. Se precisa la estimación preliminaria de los parámetros del mar de fondo usando la relación espectral quasi-lineal entre los espectros de olas y de la imagen SAR. El método se aplica a dos imágenes SAR de ERS-1 en zonas costeras.
\end{abstract}

Palabras clave: Radar de Abertura Sintética (SAR), oleaje, altura significante de las olas.

\section{INTRODUCTION}

SAR imagery of ocean waves is highly influenced by the scatterer motions, which can result in a destructive effect if the process is non-linear. The effect leads to a degradation of the azimuthal resolution in the image plane and results in an azimuthal cutoff in the spectral domain (Alpers and Bruning, 1986; Vachon et al., 1994).

Recent works have shown that in offshore conditions the intrinsic width of the spectral azimuthal cutoff, which is inversely proportional to the rms

*Received December 16, 2002. Accepted September 10, 2003. radial orbital velocity of waves, $\sigma_{r v}\left(\Theta_{i}\right)$, enables either the wind speed or the significant wave height, SWH, to be estimated (Kerbaol et al., 1998; Hogda et al., 1993; Johnsen et al., 1991).

Most works have considered only the contribution of wind waves to the root mean square (rms) and neglected the swell contribution (Kerbaol et al., 1998). However, in some sea state cases, swell must also be considered, e.g. when a swell of high amplitude propagates over a wave field driven by the local wind. In such situations, the spectral azimuthal cutoff depends on both wind waves and swell. We present a method based on an estimate of the azimuthal spectral cutoff width for estimating $S W H$ in coastal 
zones in presence of both swell and wind waves using ERS-1 SAR precision images.

\section{SAR IMAGING OF OCEAN WAVES}

Several years ago a complete non-linear (NL) model of the SAR spectrum of ocean waves was formulated (Hasselmann and Hasselmann, 1991). This model is reduced to the so-called quasi-linear (QL) model for those cases in which the waves have a long wavelength and travel close to the range direction. The relationship between the SAR image intensity spectrum, $S(\vec{k})$ and the wave height variance spectrum, $\Psi(\vec{k})$, can be written:

$$
S(\vec{k})=\frac{1}{2}\left[\Psi(\vec{k})|T(\vec{k})|^{2}+\Psi(-\vec{k})|T(-\vec{k})|^{2}\right] e^{-\left(\frac{R}{V} \sigma_{r}\left(\Theta_{i}\right) k_{x}\right)^{2}} \text { (Eq. 1) }
$$

where $\mathrm{R} / \mathrm{V}$ is the slant range-to-platform velocity ratio, $k_{x}$ the azimuthal component of the wavenumber $\vec{k}, \Theta_{i}$ the radar incidence angle, and $T(\vec{k})$ the ocean wave SAR modulation transfer function. $\sigma_{r v}\left(\Theta_{i}\right)$ is the rms radial orbital velocity of the ocean waves and is given by:

$$
\sigma_{r v}^{2}\left(\Theta_{i}\right)=\int_{0}^{2 \pi} \int_{0}^{+\infty} \omega^{2} \Psi(\omega, \Phi) G\left(\Theta_{i}, \Phi\right) d \omega d \Phi
$$

where $\omega$ is the wave angular frequency and $G\left(\Theta_{i}, \Phi\right)$ is a geometric factor depending on the incidence angle and on the wave direction $\Phi$ with respect to the azimuthal axis. For small incidence angles such as for ERS-1 $\left(\Theta_{i}=23.5^{\circ}\right), G\left(\Theta_{i}, \Phi\right)$ is nearly equal to 1 .

When wind-waves and swell are present, their respective and independent contributions, $\sigma_{r, w}^{2}\left(\Theta_{i}\right)$ and $\sigma_{r, s}^{2}\left(\Theta_{i}\right)$, to the global rms radial orbital velocity of the ocean waves, must be included as follows:

$$
\sigma_{r v}^{2}\left(\Theta_{i}\right)=\sigma_{r, w}^{2}\left(\Theta_{i}\right)+\sigma_{r, S}^{2}\left(\Theta_{i}\right)
$$

\section{Significant wave height estimation method}

A robust estimate of the azimuthal spectral cutoff width can be obtained by a least-squares fit to a Gaussian function of the SAR image azimuthal autocorrelation function, $H(x, 0)$. $H(x, 0)$ equals the inverse Fourier Transform of the SAR spectrum along the azimuthal direction $(\mathrm{y}=0)$ (Kerbaol et al., 1998). The Gaussian function is thus modelled by:

$$
H(x, 0) \approx e^{-\left(\frac{1 V x}{2 R \sigma_{r v}^{*}\left(\Theta_{i}\right)}\right)}
$$

Many studies have shown that theoretical SAR spectra are more broadbanded when computed using the NL model than using the QL model (Hogda et al., 1993; Vachon et al., 1994). Here, the parameter $\sigma_{r v}^{*}\left(\Theta_{i}\right)$ underestimates the value of $\sigma_{r v}\left(\Theta_{i}\right)$ by a factor, $\alpha$, which we have determined by simulations of the SAR ocean wave spectrum based on the QL model and on a variety of Jonswap ocean wave spectra: wind speed, U, varying from 5 to $20 \mathrm{~m} / \mathrm{s}$ and dimensionless fetch, $\xi=g X / U^{2}$, varying from 500 to 15000 ( $\mathrm{X}$ is the fetch length and $\mathrm{g}$ is the gravity acceleration). For small incidence angles as for ERS1, the influence of the wave directional spreading function on the rms radial orbital velocity is negligible. There, the rms radial orbital velocity is overridden by the rms vertical orbital velocity, independent of the wave spreading function (Alpers and Bruning, 1986).

We obtained a correction factor that increases from 1.4 to 2.0 as sea state increases (Fig. 1). Our $\alpha$ values are within the range of already published values: 1.3 (Hogda et al., 1993), 1.4 (Vachon et al., 1994) and 2.0 (Kerbaol et al., 1998).

Using an estimate of $U$ from in situ data and a rough estimate of $X$, it is then possible in each case to deduce the correction factor, $\alpha$ and then $\sigma_{r v}\left(\Theta_{i}\right)$. The total significant wave height, $S W H$, can be written:

$$
S W H=\sqrt{S W H_{S}^{2}+S W H_{W}^{2}}
$$

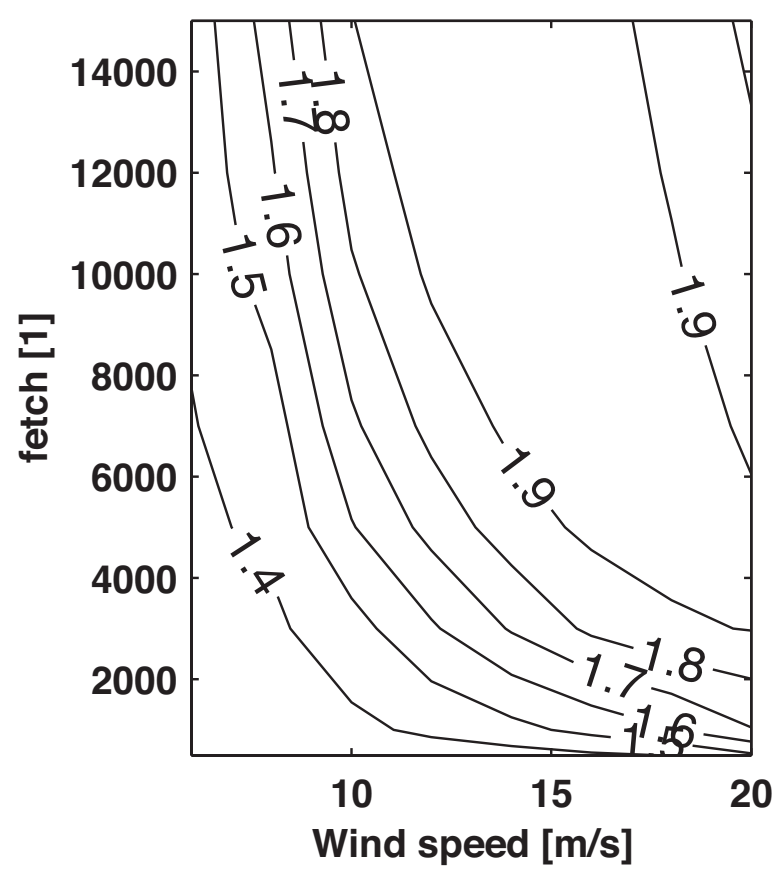

FIG. 1. $-\alpha$ variations with sea-state. 
where $S W H_{S}^{2}$ and $S W H_{W}^{2}$ are swell and wind wave significant heights respectively. The swell wavevector, $\vec{k}_{S}$, and $S W H_{S}$ are estimated from the SAR spectrum. For a monochromatic homogeneous swell, integrating the quasi-linear relationship leads to the following expression for $\mathrm{SWH}_{S}$ (Forget et al., 1995):

$$
S W H_{S}=\frac{4 m}{\left|T\left(\vec{k}_{S}\right)\right|} e^{\frac{1}{2}\left(\frac{R k_{x, S} \sigma_{r v}\left(\Theta_{i}\right)}{V}\right)^{2}}
$$

where $m$ is the rms of the SAR swell modulation. For practical computations $m$ is computed from the SAR wave modulation spectrum according to the method described in (Forget et al., 1995) which, in particular, minimises the influence of speckle on SAR estimates. Then, applying Equation 2, the rms radial orbital velocity of a monochromatic homogeneous swell at a small incidence angle is given by:

$$
\sigma_{r v, S}^{2}\left(\Theta_{i}\right)=\frac{1}{16} \omega_{S}^{2} \cos ^{2} \Theta_{i} S W H_{S}^{2}
$$

Swell angular frequency, $\omega_{S}$, is deduced from $k_{S}$ by the dispersion relationship of gravity waves in shallow water. Finally, $\sigma_{r, w}\left(\Theta_{i}\right)$ is computed from Equation 3. For small incidence angles and using a Jonswap wave spectrum, $S W H_{W}$ is given by:

$$
S W H_{W}=\frac{73.31}{g} \sigma_{r v, W}^{2.27}\left(\Theta_{i}\right) U^{0.27}
$$

Note that the influence of the fetch on $S W H_{W}$ is included in $\sigma_{r, W}\left(\Theta_{i}\right)$.

\section{CASE STUDIES}

We applied this method to ERS-1 SAR precision images. A condition of applicability is that images should present either a nearly radial swell $( \pm 15-20$ degrees to the radial direction) or a low azimuthal spectral cutoff in order to use the approximation of the QL model to estimate the swell parameters. Each SAR image is decomposed into imagettes of $3.2 \mathrm{~km}$ size.

In this study, we used two images in coastal zones. The first was obtained on March 22, 1992 at $11 \mathrm{~h} 00$ UT. The image covers the area of the AngloNormand archipelago in the English Channel. A directional wave buoy was located in the lower part of the image (Fig. 2). Half-hour estimates around the satellite path give an $\mathrm{SWH}$ of $3.3 \mathrm{~m}$. An energetic swell (period $16 \mathrm{~s}$ and $S W H_{S}=1.7 \mathrm{~m}$ ) was present in the lee of the wind. Coastal wind measurements indicated an established wind (16 m/s, 280 degree) blowing from the British coast. For this wind direction the fetch distance is estimated as $200 \mathrm{~km}$. We found a correction factor $\alpha$ of 1.9 .

The second image was obtained on January 7 , 1993 at 11h41 UT off the Mauritanian coast (Forget et al., 1995). No wave buoy data was available. Sea state conditions were obtained from the Vagatla wave prediction model (Météofrance) and exhibited a swell $\left(\mathrm{T}=14 \mathrm{~s}, S W H_{S}=1.0 \mathrm{~m}\right)$ propagating in nearrange direction over a wind wave system of $S W H_{W}$ $=1.5 \mathrm{~m}$. An east-north-easterly $10 \mathrm{~m} / \mathrm{s}$ wind from the Mauritanian coast brought about a fetch distance of $75 \mathrm{~km}$. For these conditions we found a correction factor $\alpha$ of 1.7 .

\section{RESULTS AND DISCUSSION}

The SWH fields are presented in Figures 2 and 3. For each figure, subplot A maps $S W H_{S}$ and swell wavevector estimates, and subplot B maps $S W H_{W}$. Table 1 lists the mean values and rms values of $S W H$. The $S W H$ field over the Cotentin Bay relates well with in situ data.

In water depths of less than $20 \mathrm{~m}$, the presence of rocks and breakings events is responsible for a strong degradation of the azimuthal resolution. If one restricts the analysis to water depths greater than $20 \mathrm{~m}$, the map presents a clear increase of $S W H$ off the western coast of Jersey, while the lowest values are found in the southern part, which is less open to off-shore winds. There, swell refraction is clearly visible. Nevertheless, some high $S W H_{W}$ values (greater than $6 \mathrm{~m}$ ) seem unrealistic. These are associated with high values of $\sigma_{r v}\left(\Theta_{i}\right)$ This effect may be due either to imprecision of the Gaussian fit or to the influence of increased scatterer velocity due to wave breaking events and resulting in additional azimuthal resolution degradation.

The Arguin Bank case shows a moderate sea state. The $S W H$ field indicates a slight decrease in $S W H_{S}$ values as the depth becomes shallower. Values of $S W H_{S}$ and $S W H_{W}$ are of the order of $1 \mathrm{~m}$, which is close to the values predicted by Vagatla. The highest values (around $2 \mathrm{~m}$ ) are found in the southern part, where refraction of swell is well identified.

As the method requires a good estimate of the swell wavenumber, which is computed from the 


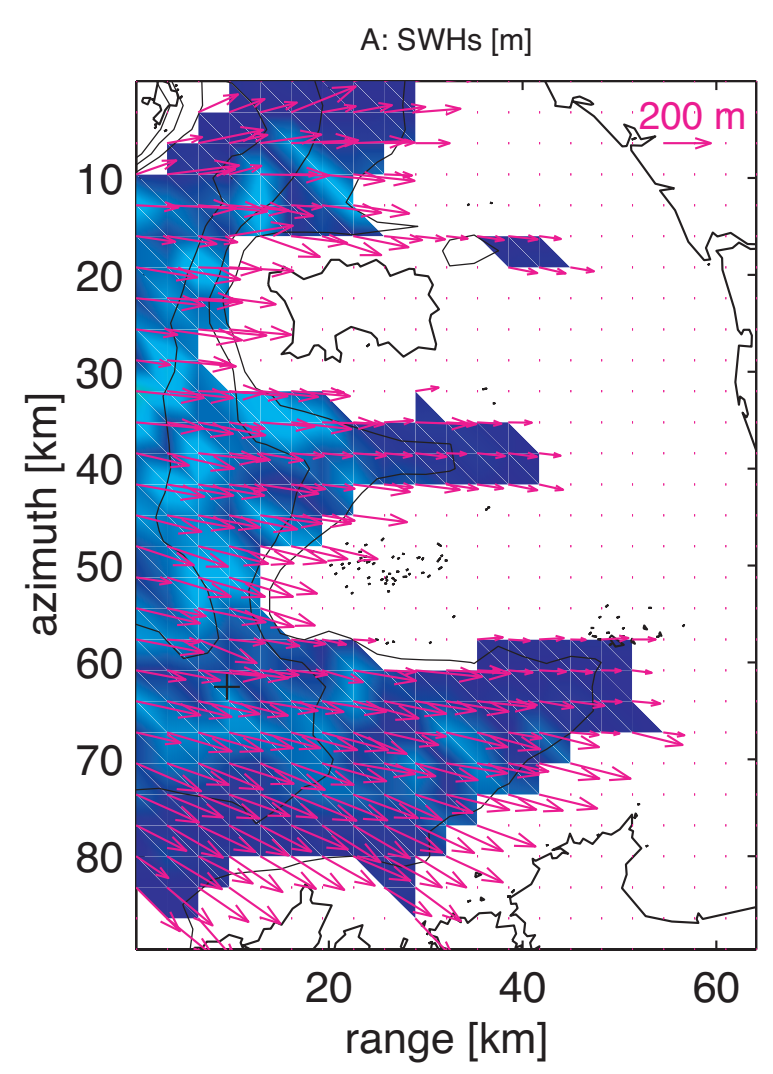

B: SWHW $[\mathrm{m}]$

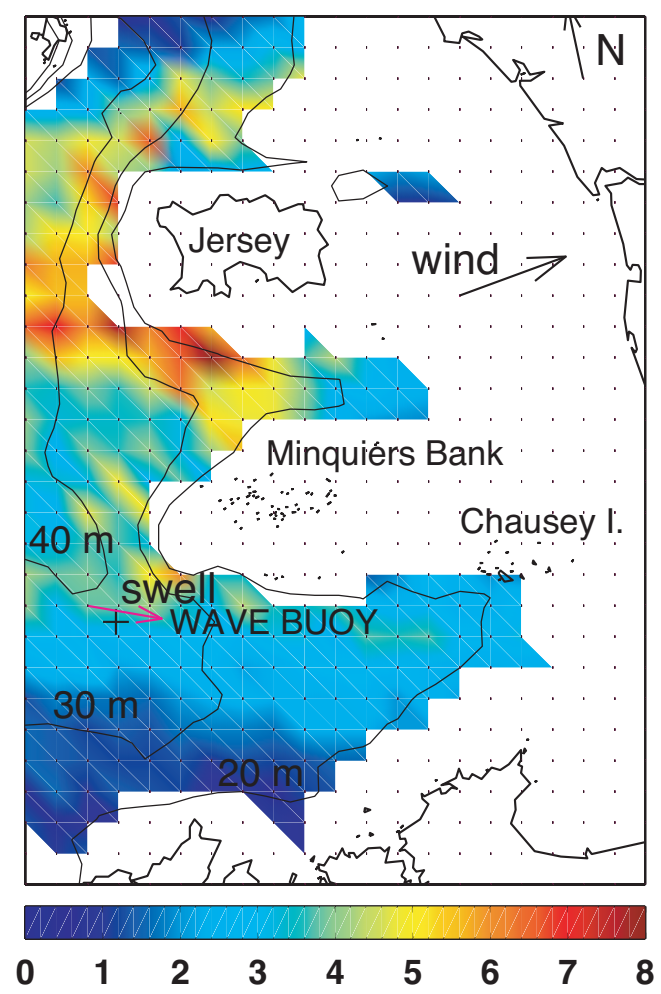

FIG. 2. $-S W H_{S}$ and $S W H_{W}$ fields in the Cotentin Bay. Subplot A: swell contribution to $S W H$ and swell wavelength vectors. Subplot B: wind waves contribution to $S W H$. Isobaths 20,30 and $40 \mathrm{~m}$ are marked.

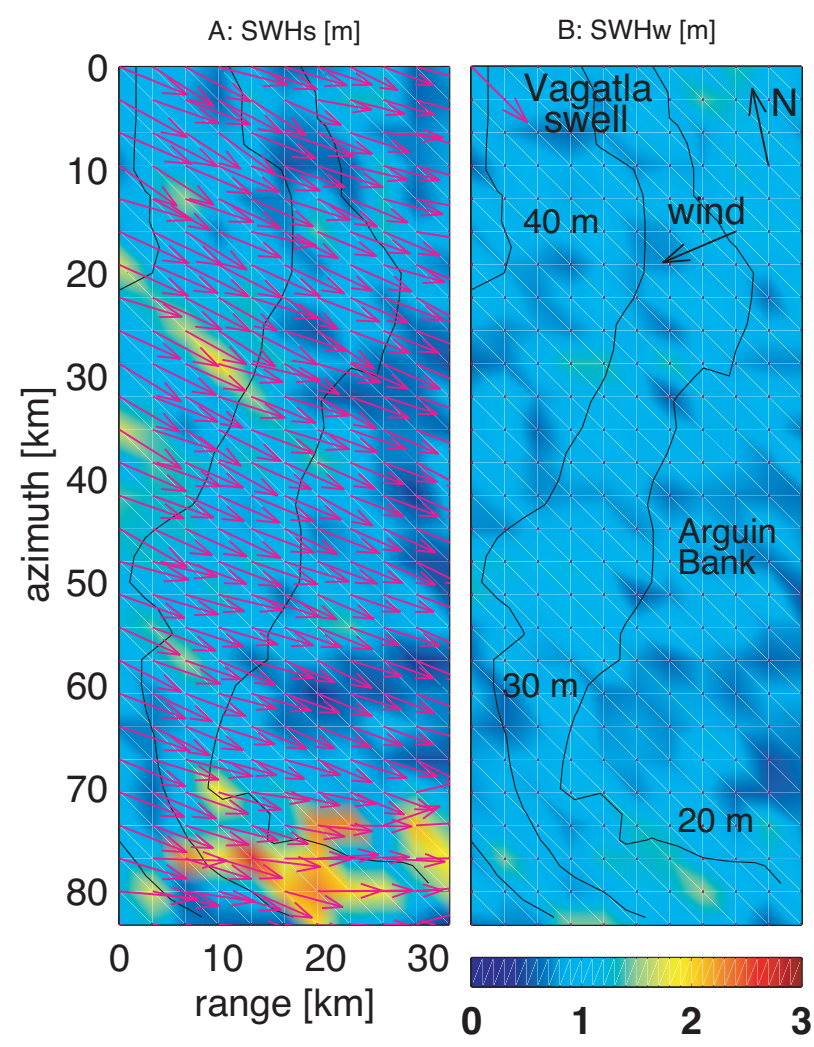

FIG. 3. $-S W H_{S}$ and $S W H_{W}$ fields over the Arguin Bank. Subplot A: swell contribution to $S W H$ and swell wavelength vectors. Subplot B: wind waves contribution to $S W H$. Isobaths 20,30 and $40 \mathrm{~m}$ are marked.

position of the swell peaks of the SAR modulation spectrum (Forget et al., 1995), we checked the quality of our estimates by comparing them with the values deduced from the dispersion relationship in shallow water. A swell period of $14.5 \mathrm{~s}$ was used (Fig. 4).

Lines on each part of the first bisector represent a deviation of the standard error of one wavenumber sample width $( \pm \Delta k=0.002 \mathrm{rad} / \mathrm{m})$. With small wavenumbers the estimate agrees well with a standard deviation of the order of $\Delta k$. As the wavenumber increases, the SAR estimates are found to be smaller than the theoretical values (Forget et al.,

TABLE 1. - Mean and rms SAR-derived $S W H$ values and sea data truth values.

\begin{tabular}{lccc}
\hline & $S W H_{S}$ & $S W H_{W}$ & $S W H$ \\
\hline $\begin{array}{l}\text { Cotentin Bay } \\
\text { mean (m) }\end{array}$ & 1.2 & 2.8 & 3.1 \\
rms (m) & 0.5 & 0.8 & 0.8 \\
mean data truth (m) & 2.3 & $\mathbf{2 . 6}$ & $\mathbf{3 . 5}$ \\
Arguin Bank & & & \\
$\quad$ mean (m) & 0.9 & 1.0 & 1.4 \\
rms (m) & 0.2 & 0.4 & 0.3 \\
mean data truth (m) & 1.0 & 1.5 & 1.8 \\
\hline
\end{tabular}




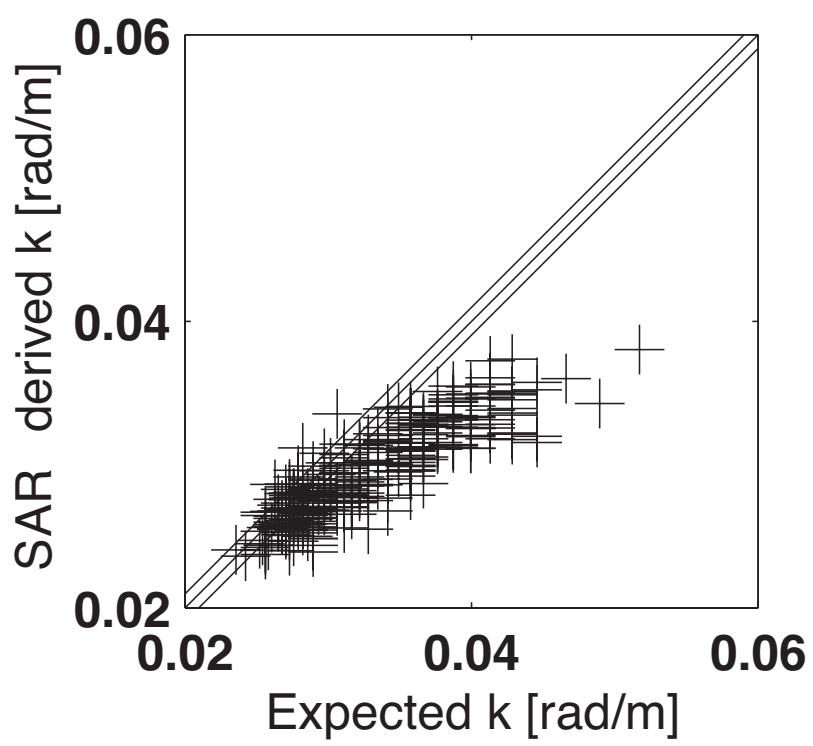

FIG. 4. - Comparison of SAR-estimated wavenumbers and theoretical wavenumbers computed from the dispersion relationship in shallow water.

1995). We interpret this increasing underestimation of the wavenumber as due to an increased influence of the spectral cutoff where the swell wavenumber increases in shallower waters (Alpers and Bruning, 1986). For a given cutoff width, as the swell wavenumber increases with decreasing depth, the swell vector rotation towards the range axis is more pronounced and produces an increased underestimation of the swell azimuthal wavenumber component. The wavenumber shift, $\delta k$, is:

$$
\delta k=k_{0}\left(1-\sqrt{\sin ^{2} \Theta_{0}+\cos ^{2} \Phi_{S A R}}\right)
$$

where $k_{0}$ is the swell wavenumber in deep water, $\Phi_{0}$ the true swell direction and $\Phi_{S A R}$ the swell SARderived direction. We found in both cases that the observed coastal shifts are of the same order as the theoretical shifts (Rousseau, 1998).

\section{CONCLUSION}

We have presented a method for estimating the significant wave height in coastal zones from SAR images when the sea state consists of two systems, a long wave system (swell) and a short (wind) wave system. The method uses a parametrisation of the wind wave spectrum by a Jonswap model. The method requires an estimate of the wind vector that can be obtained from coastal mesoscale wind mod- els such as PERIDOT (MétéoFrance) or HIRLAM. The method is based on the separation of the wind waves and swell contributions to the spectral azimuthal cutoff width and the estimate of the swell energy from the SAR modulation spectrum using the quasi-linear relationship. Using ERS-1 SAR data, the method allows a unique and relatively high resolution description of $S W H$ variation $(3.2 \mathrm{~km})$. The results can be seen to relate well with in situ buoy or model data but some high values can be found locally. We relate this effect to non-orbital motions inducing an additional degradation of the azimuthal resolution.

\section{ACKNOWLEDGMENTS}

We warmly thank the French maritime service (STNMTE) and MétéoFrance for providing us with in situ data and C. Valerio (CETE) for the SAR image of the Bay of Cotentin. S. Rousseau's postdoctoral at ICM was supported by the EU MAST programme under contract MAS3-CT97-5051.

\section{REFERENCES}

Alpers W.R. and C. Brüning. - 1986. On the relative importance of motion-related contributions to the SAR imaging mechanism of ocean surface waves, IEEE transactions on Geoscience and Remote Sensing, 24: 873-885.

Brüning C., W. Alpers and K. Hasselmann. - 1990. Monte-Carlo simulation studies of the nonlinear imaging of a two dimensional surface wave field by a synthetic aperture radar, Int. J. Remote Sensing, 11: 1695-1727.

Forget F., P. Broche and F. Cuq. - 1995. Principles of swell measurements by SAR with application to ERS-1 observations off the Mauritanian coast, Int. J. Remote Sensing, 16: 2403-2422.

Hasselmann K. and S. Hasselmann. - 1991. On the nonlinear mapping of an ocean wave spectrum into a synthetic aperture radar image spectrum and its inversion, J. Geophys. Res., 96: 1071310729.

Hogda K.A., S. Jacobsen, H.E Krogstad and G. Engen. - 1993. Azimuth smearing in ocean-synthetic aperture radar image spectra: A study of Hasselmann's closed-form transformation based on Norwegian continental shelf experiment 1988 synthetic aperture radar data, Radio Science, 28: 501-512.

Johnsen H., K.A. Hogda, T. Guneriussen and J.P. Pedersen. - 1991. Azimuth smearing in synthetic aperture radar ocean image spectra from the Norwegian continental shelf experiment of 1988, J. Geophys. Res., 96: 10443-10452.

Kerbaol V., B. Chapron, P.W. Vachon. - 1998. A global analysis of ERS-1/2 SAR wave mode imagettes, J. Geophys. Res., 103: 7833-7846.

Rousseau S. - 1998. Analyse d'images radar à ouverture synthétique aéroportées et satellitales pour estimer l'état de la mer. PhD Thesis, Université de Toulon et du Var, France.

Vachon P.W., H.E. Krogstad and S. Paterson. - 1994. Airborne and spaceborne SAR observations of ocean waves. Atmospheric Ocean, 32: 83-112.

Scient. ed.: J. Font 